Research Paper

\title{
Sleep disorders related to nutrition and digestive diseases: a neglected clinical condition
}

\author{
Filippo Vernia, Mirko Di Ruscio, Antonio Ciccone, Angelo Viscido, Giuseppe Frieri, Gianpiero Stefanelli, \\ Giovanni Latella ${ }^{\varpi}$ \\ Division of Gastroenterology, Hepatology and Nutrition, Department of Life, Health, and Environmental Sciences, University of L'Aquila, Piazza S. Tommasi, 1- \\ Coppito, 67100 L'Aquila, Italy. \\ $\triangle$ Corresponding author: Giovanni Latella, MD, Gastroenterology, Hepatology and Nutrition Division, Department of Life, Health and Environmental \\ Sciences, University of L'Aquila, Piazza S. Tommasi, 1- Coppito, 67100 L'Aquila, Italy. E-mail: giolatel@tin.it; Telephone: +39-0862-434-735; Fax: +39-0862-433- \\ 425. \\ (c) The author(s). This is an open access article distributed under the terms of the Creative Commons Attribution License (https://creativecommons.org/licenses/by/4.0/). \\ See http:/ /ivyspring.com/terms for full terms and conditions.
}

Received: 2020.03.01; Accepted: 2020.10.04; Published: 2021.01.01

\begin{abstract}
Sleep disturbances often result from inappropriate lifestyles, incorrect dietary habits, and/or digestive diseases. This clinical condition, however, has not been sufficiently explored in this area. Several studies have linked the circadian timing system to the physiology of metabolism control mechanisms, energy balance regulation, and nutrition. Sleep disturbances supposedly trigger digestive disorders or conversely represent specific clinical manifestation of gastrointestinal (GI) diseases. Poor sleep may worsen the symptoms of Gl disorders, affecting the quality of life. Conversely, short sleep may influence dietary choices, as well as meal timing, and the circadian system drives temporal changes in metabolic patterns. Emerging evidence suggests that patients with inappropriate dietary habits and chronic digestive disorders often sleep less and show lower sleep efficiency, compared with healthy individuals. Sleep disturbances may thus represent a primary symptom of digestive diseases. Further controlled trials are needed to fully understand the relationship between sleep disturbances, dietary habits, and GI disorders. It may be also anticipated that the evaluation of sleep quality may prove useful to drive positive interventions and improve the quality of life in a proportion of patients.

This review summarizes data linking sleep disorders with diet and a series of disease including gastroesophageal reflux disease, peptic disease, functional gastrointestinal disorders, inflammatory bowel diseases, gut microbiota alterations, liver and pancreatic diseases, and obesity. The evidence supporting the complex interplay between sleep dysfunction, nutrition, and digestive diseases is discussed.
\end{abstract}

Key words: sleep disorders; circadian rhythm; diet; nutrition; gastrointestinal disease; digestive diseases

\section{Introduction}

Sleep disorders affect many individuals worldwide and their prevalence is increasing. It has been estimated that up to 70 million people in the US and 45 million in Europe suffer from a chronic sleep disorder that adversely affects health and quality of life (QoL) [1,2].

Sleep disorders are considered as risk factors for mortality, and two meta-analyses have reported an increased mortality rate among short sleepers [3,4]. Pooled analyses of the work by Cappuccio et al. indicates that short sleepers (commonly defined as $<7$ $\mathrm{h}$ per night, by fewer authors as $<5 \mathrm{~h}$ per night) have a $12 \%$ greater risk, and long sleepers ( $>8$ or $9 \mathrm{~h}$ per night) a $30 \%$ greater risk of dying than those sleeping
7 to $8 \mathrm{~h}$ per night [3]. Similar results have been obtained by Ge et al., reporting assessing that difficulty in falling asleep (DFA) and non-restorative sleep (NRS) were associated with an increased risk of all-cause mortality (DFA: $\mathrm{HR}=1.13,95 \%$ : CI 1.03 to 1.23, $p=0.009$; NRS: $\mathrm{HR}=1.23,95 \% \mathrm{CI}: 1.07$ to $1.42, p=$ 0.003) [4]. Sleep disorders are estimated to favor drowsiness and represent the underlying cause of $15-20 \%$ of road accidents [5]. Similarly, $13 \%$ of work injuries can be attributed to sleep problems [6].

A precise evaluation of costs deriving from sleep disorders is difficult. Their total cost in Europe was estimated at $€ 35.4$ billion in 2010 [2]. According to the Australian Sleep Health Foundation, the direct cost 
associated with the three commonest sleep disorders, obstructive sleep apnoea syndrome (OSAS), primary insomnia, and restless leg syndrome (RLS) was $\$ 818$ million and the indirect costs exceeded $\$ 4.3$ billion in 2010 [7]. Similar findings have been reported by the Italian Ministry of Health, which put the direct and indirect cost of OSAS in 2014 at $€ 2,9$ billion [8].

Sleep disorders are not limited to western countries but are increasingly frequent in developing world. According to a recent study of Asian and African patients, $16.6 \%$ of participants had severe nocturnal sleep problems [9].

The International Classification of Sleep Disorders (ICSD) is the key reference for the diagnosis of sleep disorders, classified in seven major categories: insomnia disorders, sleep-related breathing disorders, central disorders of hypersomnolence, circadian rhythm sleep-wake disorders, sleep-related movement disorders, parasomnias, and other sleep disorders [10,11].

Sleep disorders are related to a variety of causes that prevent the straightforward identification of the primary mechanism involved in individual patients, but are often related to poor diet, inappropriate lifestyle and dietary habits, and/or digestive diseases. Indeed, a close relationship is widely documented between brain and nutrition/metabolism, as well as between brain and digestive organs. (Fig. 1) [12-15]. However, little is known about the clinical impact of this emerging issue.

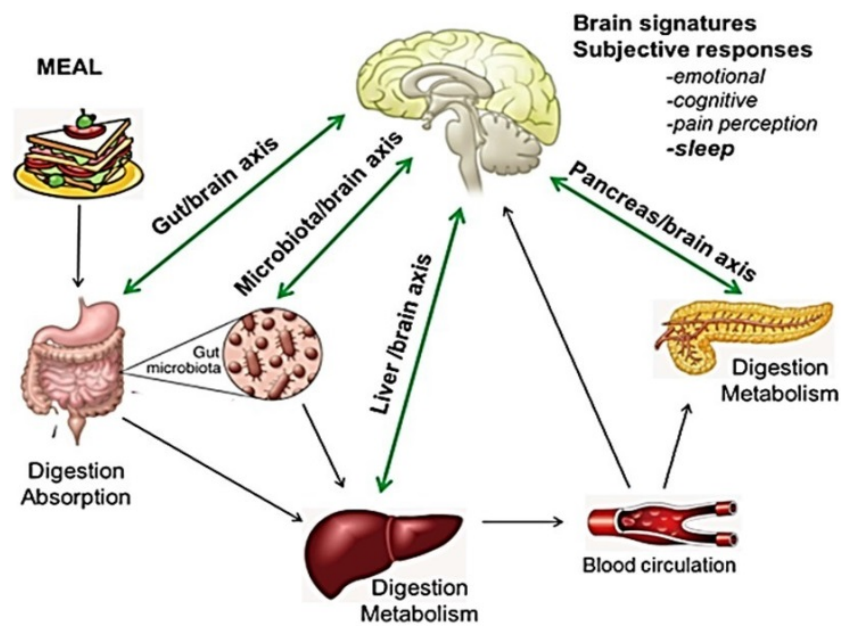

Figure 1. Bidirectional interaction between GI tract, liver, pancreas, and brain: food and gut-brain connection. The central nervous system (CNS) plays a role in regulating function and homeostasis of the gastrointestinal tract. Nutrients affect the production of hormones, including growth hormone, prolactin, testosterone, melatonin, and serotonin, all playing a role in the regulation of the circadian rhythms and brain function. Similarly, digestive hormones and enteroendocrine secretions (GLP-1, GIP, serotonin, substance $P$ and peptide YY) also activate visceral afferent endings. Pancreatic endocrine secretion, through glucose homeostasis, insulin-resistance and GLP-1 activity is also implicated in the crosstalk between gut and neurological function. Impairment of liver detoxifying processes results in increased concentrations of false neurotransmitters and CNS-acting toxins. The gut flora also influences the CNS, regulating the architecture of sleep, stress reactivity and behavior. Bacterial metabolic products and inflammatory cytokines have been proposed as possible mediators. Adapted from E. M. Candeias et al. World J Diabetes 2015;6:807-827.
The aim of this review is to discuss and summarize the current evidence on the role of dietary habits, and GI conditions, in sleep disorders, identifying therapeutic gaps and opportunities. Limitations of recently performed studies, will underline the need for additional, multi-specialist, clinical trials to elucidate the complex bidirectional interaction between sleep disorders and GI tract diseases.

\section{Materials and methods}

A systematic electronic search of the scientific literature up to January 2020 was performed using Medline, EMBASE, Web of Science, Scopus, and the Cochrane Library. The search strategy used a combination of Medical Subject Headings (MeSH) and keywords as follows: "sleep", "sleep disorders", "circadian clock", "circadian rhythm", "arousal", "awakening", "diet", "nutrition", "nutrients", "energy balance", "metabolism", "metabolic syndrome", "eating habits", "food intolerances", "lactose intolerance", "gluten intolerance", "food allergies", "gastrointestinal disease", "gastroesophageal reflux disease", "peptic disease", "ulcer", "nausea", "vomiting", "functional dyspepsia", "eructation", "rumination", "irritable bowel syndrome", "functional flatulence", "constipation", "diarrhea", "incontinence", "anorectal pain", "inflammatory bowel disease", "IBD", "coeliac disease", "gut microbiome", "gut microbiota", "dysbiosis", "gut-brain axis", "liver diseases", "cirrhosis", "hepatic encephalopathy", "chronic hepatitis", "acute hepatitis", "non-alcoholic fatty liver disease", "non-alcoholic steatohepatitis", "pancreatic diseases", "chronic pancreatitis", "acute pancreatitis", "pancreatic insufficiency", "non-alcoholic fatty pancreatic disease", "overweight", "obesity", "obstructive sleep apnoea". Relevant articles were identified by screening the abstract; additional studies were identified by a manual search of the reference list of studies and review articles. The great majority of articles reported in the present review did not use the ICSD-3 classification, minimizing the possibility to categorize the interaction between different conditions and the mechanisms of sleeping disorders.

\section{Nutrition and sleep disorders}

A healthy diet and lifestyle, and correct eating habits contribute to psychological and physical wellbeing, sleep included, whereas an inappropriate diet and limited physical activity impair the quality of sleep [16,17].

Eating too quickly or skipping meals, overabundant meals, irregular mealtimes, and poor food quality, all are dietary causes of sleep disorders. 
Spicy food, stimulants, and adverse food reactions (intolerances and food allergies) may be additional factors.

The eating behavior affects quality and quantity of sleep in humans [18]. A consistent association between short sleep and a high total energy intake has also been described [19]. Nutrients may affect the production of hormones, including growth hormone, prolactin, testosterone, melatonin, and serotonin, all of which play a role in regulating the circadian clock. Nutrients favoring or inhibiting their release influence the quality of sleep, whereas foods acting on tryptophan availability or the synthesis of serotonin and melatonin promote sleep [20]. Some vitamins (B1 and B6) also induce production and release of melatonin and serotonin [21, 22].

Stimulants, like coffee, cola beverages, spices, tea, and chocolate may also adversely affect sleep [23]. Alcohol, one of the most powerful depressants, alters the circadian clock and worsens the quality of sleep [24]. Spicy and hot foods are associated with insomnia [25].

The timing of meals, especially frequency and regularity of snacks, desynchronize circadian rhythm, affect metabolism, and favor obesity [26, 27]. This is consistent with the role of the circadian clock in regulating the release of hormones and neurotransmitters involved in sleep control.

Skipping meals and eating a single, large evening meal is increasingly common in industrialized countries. However, shifting the main calorie intake to the end of the day adversely affects digestion and makes sleep difficult due to GI symptoms such as gastro-esophageal reflux (GERD), dyspepsia, and nausea; more so if the meal is abundant and fat-rich [28]. Conversely, the role of carbohydrates on sleep patterns is still debated [29, 30] and the weight of carbohydrates versus caloric load is controversial.

Stress is important in influencing eating patterns, possibly through alterations in the hypothalamicpituitary-adrenal axis favoring the consumption of junk food (high in fat and refined sugar) [31].

Sedentary lifestyle and short sleep time are associated with poor eating habits, and favor high energy intake [32-34]. Limited physical activity during the day has been related to food consumption at night, which in turn promotes the metabolic syndrome and obesity and, again, adversely affects the circadian clock [35].

Food allergies and intolerances, involving lactose and gluten (coeliac disease and gluten sensitivity), also have a negative influence on sleep patterns [36]. The presence in food of amino acids such as phenylalanine, histamine, and tyramine, promotes production and release of adrenaline, noradrenaline, and other stimulant neurotransmitters, may impair sleep.

According to some authors, the relationship between meals and sleep is reciprocal, since the circadian system drives temporal changes in metabolic patterns while changes in metabolic or nutritional status alter the circadian rhythm [37].

The release of some hormones involved in metabolism - e.g. glucagon, insulin, ghrelin, leptin, and corticosterone - is associated with a well-set circadian rhythm [38]. Sleep disturbances alter the energy balance and may induce weight gain [39], obesity, and type 2 diabetes $[40,41]$. The underlying mechanisms are largely unknown [42], but several lines of evidence link the circadian timing system to the physiology of metabolism and nutrition [43,44]. Changes in neuroendocrine system activity are the main mediators of insufficient sleep, by increasing appetite, enhancing sensitivity to food stimuli, and favoring high energy intake [45].

Poor sleep is related to changes in the circulating concentration of melatonin, cortisol, ghrelin, and leptin [46-49]. Other examples include daily fluctuations of glucose levels, insulin sensitivity, and postprandial response $[37,50]$. Thus, the disruption of the circadian rhythm and sleep loss may help inducing the metabolic syndrome [51].

Ghrelin acts as a neuropeptide and participates in sleep-wake regulation. Systemic ghrelin infusion promotes non-REM sleep in males, both humans and mice, but not in healthy women [52].

Brain histamine regulates arousal, circadian, and eating rhythms. $\mathrm{H} 3$ receptor, which triggers its effect on sleep, is among the treating targets for sleeping disturbances $[53,54]$.

Sleep restriction has been associated with reduced concentrations of the satiety factor leptin, and increased concentrations of the hunger-promoting hormone ghrelin, altering their ability to signal the correct caloric requirement $[48,49]$. The dynamic interplay between the digestive system and sleep is an excellent example of the brain-body interaction (Fig.1) [12-15]. The hypothalamus, particularly the lateral hypothalamic area, regulates the energy balance and coordinates peripheral cues of energy status, and weight-affecting behaviors. Lateral hypothalamic neurons expressing neuropeptides like melaninconcentrating hormone and orexin/hypocretins, through distinct circuits, play an important role in regulating the ingestion of food, arousal, locomotor behavior, and autonomic functions [56]. Orexins provide a link between energy homeostasis and vigilance state and are involved in the dopaminergic reward system $[57,58]$. Mutation of orexin-producing 
genes induces an altered sleep phenotype in animal models. High activity of orexin-producing cells during wake periods and almost none during sleep has also been hypothesized to impair sleep [59].

Mounting evidence also suggests that sleep influences dietary choices. Individuals who sleep less are more likely to prefer energy-rich foods (e.g. fats and refined carbohydrates), eat fewer vegetables, and choose irregular eating patterns [60-63].

\section{Digestive diseases and sleep disorders}

Sleep disturbances and sleep deprivation induce a variety of visceral disorders [64] but may also be the symptoms of other diseases. Patients with chronic disorders often report short sleep or show a lower sleep quality, alone or associated with other symptoms, when compared to healthy individuals. [65]. Poor sleep may also worsen the subjective symptoms of the disorders, affecting QoL [66].

The GI diseases that most frequently impair sleep are acid-related (GERD, peptic disease), functional diseases, inflammatory GI disorders, liver diseases, overweight, and obesity.

\section{Gastro-esophageal reflux disease}

GERD is characterized by pathological acid or non-acid reflux and is associated with a variety of disturbances that may affect the upper GI tract (regurgitation, heartburn, pain) and/or induce respiratory symptoms (hoarseness, dysphonia, chronic laryngitis, cough, asthma, and chronic bronchitis). Awakenings due to heartburn, dyspepsia, acid brash, coughing, or choking are a major cause of sleep disruption $[66,67]$. There is strong evidence for a bidirectional relationship between GERD and sleep disturbances, since GERD symptoms cause difficulty falling asleep, sleep fragmentation, and early morning awakenings, while in turn sleep deprivation appears to induce esophageal hyperalgesia [68]. Thus, GERD patients with sleep disturbances report more severe symptoms and a worse QoL than those without sleep disturbances [69]. The association between GERD and sleep disturbances has been recently confirmed by two different trials on Australian and Japanese patients [70,71]. Interestingly, a study by Hoshino reported that approximately one-third of the patients with GERD and sleep disturbance had non-acid reflux [72]. In these patients, high prevalence of anxiety and depression has been reported, the latter being to some extent directly mediated by poor sleep $[70,71]$.

An association between GERD and sleep apnea is frequently reported [73]. Reflux patterns are different during arousal and sleep, due to delayed gastric emptying, reduced peristalsis, reduced salivary secretion and swallowing, and prolonged esophageal clearing time during sleep.

GERD may be overlooked when patients fail to report common signs and symptoms (regurgitation, heartburn, substernal pain), which the patient does not consider relevant in sleep disturbances. A recent meta-analysis suggests that treatment with proton pump inhibitors (PPIs) for GERD improves the quality of sleep [74]. Nutritional and behavior modification may prove useful besides PPIs and prokinetics: avoid large/late-night meals may help preventing reflux [69]. Avoiding going to bed soon after the evening meal, smoking, eating fat-rich or acid foods, mint, chocolate, coffee, tea, fizzy drinks may be helpful. Weight loss may be considered as well as raising the bed headrest by $15-20 \mathrm{~cm}$, in the most severe cases.

\section{Peptic disease}

Peptic disease is characterized by specific symptoms including epigastric pain, heartburn, a sense of hunger or satiety, nausea, and vomiting, associated to gastric or duodenal mucosal lesions. Gastric acid secretion plays a central role in the pathogenesis.

Patients with duodenal ulcers often wake up during the night due to heartburn and epigastric pain, relieved by food, whereas gastric ulcers are associated with earlier postprandial symptoms, making digestion hard and causing epigastric pain, resulting in difficulties in falling asleep. Pain awakening affects two-thirds of patients with duodenal ulcers and one-third of those with gastric ulcers [75]. PPI treatment associated, if needed, with Helicobacter pylori eradication, improves sleep quality in patients with peptic disease [74]. Dietary recommendations consist in reducing protein, salt and calcium consumption, which induce gastric acid secretion. This proves most useful in the early or acute stages of the disease [76]. Patients with gastric ulcer should reduce lipids as well, due to the unfavorable effect on gastric emptying [77].

Longer sleep duration may play a protective role against the development of peptic ulcers [78] whereas the disruption of the circadian rhythm by sleep disturbances or shift work, may favor in peptic ulcer disease [79].

\section{Functional gastrointestinal disorders}

Functional disorders involving the upper GI tract (functional dyspepsia, eructation, nausea, vomiting, and rumination), the small and large bowel (irritable bowel syndrome [IBS], functional flatulence, functional stipsis/constipation, functional diarrhea), and the anorectum (functional anorectal pain, incontinence and functional rectal outlet obstruction) 
are often associated with sleep disorders. Impaired sleep quality and chronic fatigue are frequently reported in these patients. Recent data from 3600 Chinese patients with functional gastrointestinal disorders, indicate that excessive daytime sleepiness is present as well [80].

Symptoms may be triggered or exacerbated by stress or by nutrients. Patients with functional dyspepsia, besides treatment with prokinetics and anti-secretory medications, should adopt specific dietary restrictions [81,82] of pro-secretory food including proteins, salt, and calcium. Lipids, slowing gastric emptying [83] should also be cut down in functional dyspepsia.

Sleep disturbances are well documented in IBS patients. Difficulty falling asleep, short sleep time, frequent arousals and awakenings, and nonrestorative sleep are common $[84,85]$. The association is confirmed by two large trials, carried out the general population and nurses, especially in the presence of depression [86,87]. A recent meta-analysis including 36 studies with 63620 participants, reported a $37.6 \%$ prevalence of sleep disorders in IBS patients [88].

Although the underlying mechanisms are still unclear, decreased orexin signaling may play a role in the pathogenesis of the functional GI disorder in some patients suffering from sleep disturbances [89]. Melatonin modulates GI motility and sensitivity in IBS patients, through still unidentified mechanisms [90] and exerts analgesic effects in patients with chronic pain (e.g. IBS) [91].

Abnormal sensitivity to some nutrients, including lactose, gluten, and fermentable oligosaccharides, disaccharides, monosaccharides and polyols (FODMAPs) have often been reported in functional intestinal disorders [92], but the role of negative expectations after ingesting some food should be ruled out [93].

In patients with suspected functional symptoms, primary or secondary motility disorders (diabetes, neurodegenerative diseases) favoring small intestinal bacterial overgrowth (SIBO) should be ruled out. This condition characterized by an abnormal bacterial fermentation in the small bowel may mimic functional symptoms as well as abdominal pain worsening [94] and sleep disruption [95]. SIBO should always be considered in patients undergoing prolonged PPI use and profound acid inhibition [96].

\section{Inflammatory intestinal disorders and celiac disease}

Chronic inflammatory bowel diseases (IBD) are held to be a risk factor for sleep, but the available data are inadequate and largely inconclusive.
Inflammatory cytokines such as tumor necrosis factor- $\alpha$ (TNF-a), interleukin (IL) -1, and IL-6 cause sleep disturbances, while sleep deprivation upregulates cytokines [97], particularly IL-1 and TNF-a. Clinical studies identified an association between sleep disturbances, disease activity, subclinical inflammation, and risk of IBD relapse [98-100]. A recent trial reported that poor sleep quality, evaluated using the Pittsburgh Sleep Quality Index, was associated to the absence of mucosal healing $(P<0.05)$ [101]. An improvement in sleep and mood quality was observed in patients responding to anti-TNF-a or vedolizumab [102]. Conversely, the association between IBD and sleep disorders has been questioned by a study objectively measuring sleep parameters by actigraphy, urine melatonin metabolites and two different sleep quality indexes [103]. These data are in line with other reports suggesting the importance of IBS-like symptoms on the sleep quality of IBD patients in clinical remission [104].

Data regarding sleep impairment in coeliac disease are scarce and contradictory. Breathing disorders during sleep, ranging from primary snoring to obstructive sleep apnea, have been reported, with gas exchange abnormalities and sleep fragmentation [105]. According to a recent study, coeliac patients are at high risk of poor sleep, both before and after diagnosis [106]. Other data are conflicting, supporting [107] or failing to confirm sleep problems in coeliac disease [108]. Similarly, pediatric coeliac patients less likely present with OSA-related symptoms as compared to healthy controls. Nonetheless, glutenfree diet induced significantly improvement in those who had symptoms [109].

\section{Gut microbiota alterations}

The alterations of the gut microbiota, besides being responsible for several gastrointestinal disorders, seem to be involved in sleep disorders. The gut microbiome affects the brain through many mechanisms. Several metabolites such as short chain fatty acids, biliary acid metabolites, and neuroactive substances (gamma aminobutyric acid, tryptophan precursors and derivatives, serotonin, and catecholamines) produced by bacteria, as well as cytokines released during the immune response mediate microbiome-host interactions [110-112]. The influence of these signals has been documented in animal models [113] and seems to play a role in the development of the nervous system [114].

The gut microbiota is involved in shaping the hypothalamic-pituitary-adrenal axis in relation to sleep and the stress reaction [15,95]. It is also likely 
involved in the regulation of motivated behavior and emotions (Fig. 2) [115,116].

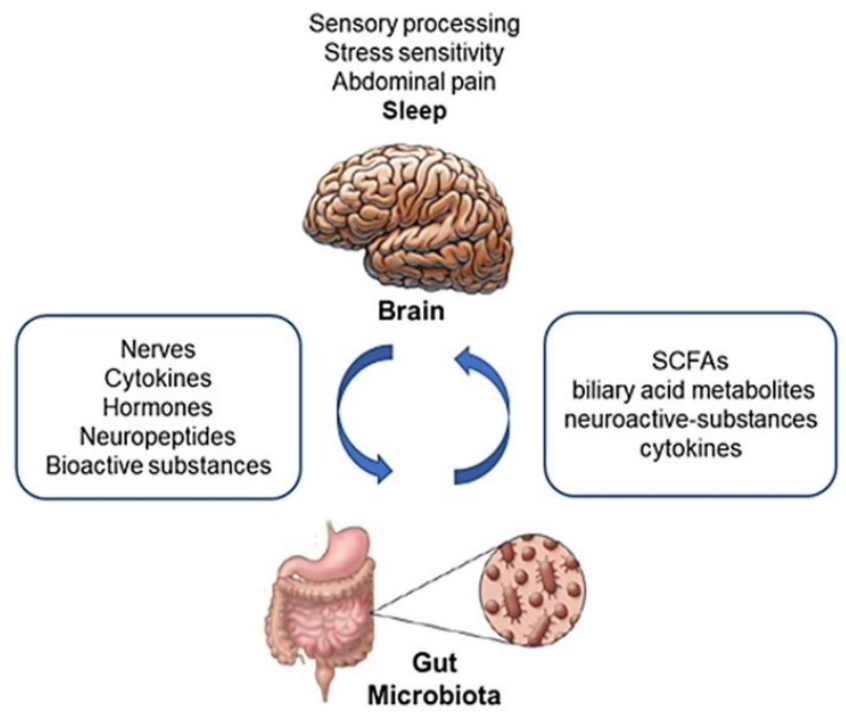

Figure 2. Bidirectional interaction among the gut microbiota and the brain. The gut microbiome affects the brain through a variety of mechanisms, producing or modifying several metabolites, neuroactive substances and cytokines. On the other hand, the Enteric Nervous System, receiving efferent information from the brain through autonomic neural connections and hormonal pathways, modulates gastrointestinal motor function, gastric secretion, intestinal absorption and secretion and gut-associated immune system, which all may impact on the composition and metabolism of the gut flora. SCFAs: Short Chain Fatty Acids. Adapted from Chen X, Protein Cell 2013;4:403-14.

An extensive bidirectional communication network between the GI tract and the central nervous system (CNS), referred to as the "gut-brain axis", has been widely investigated in the past decade (Fig. 1) [12-15]. Recent studies linked psychiatric disorders, including depression, to changes in the microbiome $[117,118]$. A large proportion of depressed patients present with changes in appetite and sleep (difficulty falling asleep, difficulty staying asleep, low sleep quality) that significantly impair their daily life. Data focused on sleep, however, are scarce [119].

Short sleep duration induces a physiological stress response, which in turn disrupts the normal balance of intestinal microbiota. People suffering from jetlag, shift work, early morning starts, and late bedtimes have altered intestinal microbial balance and dysbiosis $[119,120]$.

Sleep and circadian rhythm disruption may alter the gut microbiota in humans, contributing to the development of metabolic disease [121]. Sleep loss has been hypothesized to induce blood-brain barrier disruption in rodents. The underlying mechanism is unknown, but sleep loss has been postulated to induce low-grade systemic inflammation, releasing cytokines, chemokines, and acute-phase proteins [122].

Gut dysbiosis also seems to play a role in the development of OSA-induced hypertension [123].
These hypotheses have been questioned by a small study that aimed at exploring whether improving sleep duration is associated with changes in gut microbiota in chronically sleep-deprived individuals. The study failed to identify significant changes after two weeks of observation. The relationship between gut microbiota and sleep, if present, is thus still to be elucidated [124].

\section{Liver diseases}

Sleep disorders may occur in both acute and chronic hepatitis but are more common in cirrhotic patients. A considerable proportion of patients with cirrhosis and acute or chronic liver failure suffer from insomnia, delayed sleep, and excessive daytime sleepiness. This association has been recently confirmed by a study on 341 patients with viral liver cirrhosis, reporting a significant elevation of the Pittsburgh Sleep Quality Index [125]. Abnormal polysomnographic findings are also present [126]. Sleep disturbances have been attributed to hepatic encephalopathy (HE). According to recent guidelines, HE can be subdivided into overt and covert HE [127]. Covert HE, corresponding to mild or grade I disease according to West Haven criteria, affects up to $80 \%$ of cirrhosis patients [128]. Sleep disturbances often are an early sign of $\mathrm{HE}$, leading to daily sleepiness, increased risk of injuries, and impairing QoL $[129,130]$. Covert HE is clinically underdiagnosed, unless specific tests are performed, such as the paper-pencil test or the Inhibitory Control test. No clear correlation has been found between sleep disturbances and $\mathrm{HE}$, but some studies suggest impaired melatonin metabolism [131], since the response of melatonin to light is decreased in cirrhosis [132]. The gut microbiota is involved in HE, as shown by the clinical improvement following lactulose or rifaximin, which reduce fermentation [133-135]. Supplementation with oral branched chain amino acids has been reported to improve sleep in cirrhosis without encephalopathy, lessening the production of false neurotransmitters like octopamine by aromatic amino acids [136].

A recent meta-analysis involving 21 trials and 1420 participants suggested that probiotics may reduce the risk of developing overt $\mathrm{HE}$ and high plasma ammonia, thus improving QoL compared with placebo or no intervention [137].

Sleep disturbances have been reported in $60 \%$ of patients with chronic C virus (HCV) hepatitis $[138,139]$. Moreover, complications of interferon a (used for the treatment of $\mathrm{HCV}$ ) sometimes consist in sleep disorders $[138,140]$.

The neural and humoral communication pathways between liver and brain are not fully 
understood, but a role is played by inflammatory cytokines such as TNF-a, IL-1, and IL-6, which alter the concentration of central neurotransmitters (serotonin and corticotrophin-releasing hormone) (Fig. 3) [141,142].

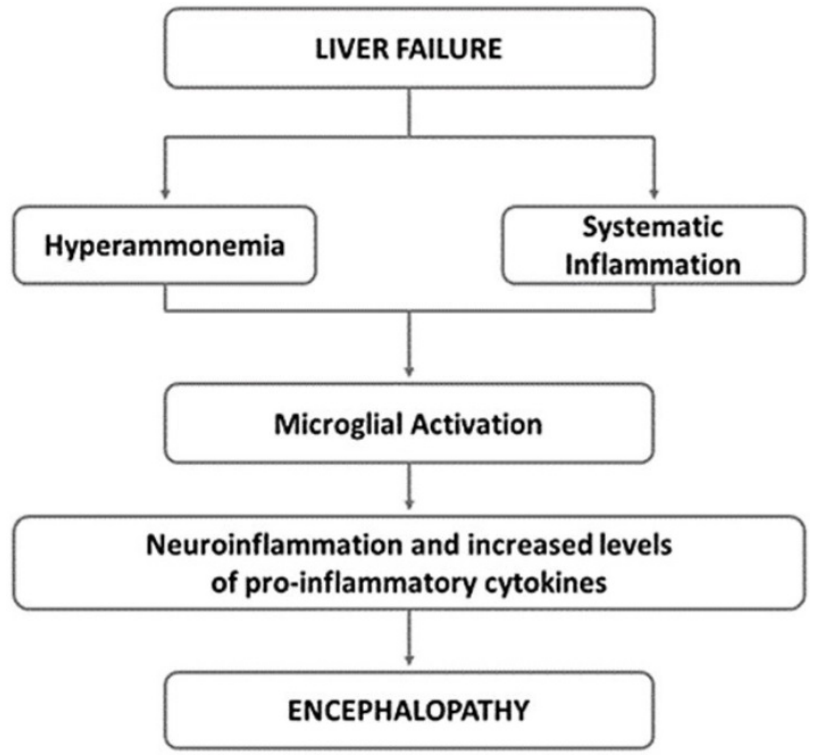

Figure 3. Underlying mechanisms of hepatic encephalopathy. Neuroinflammation is common in hepatic encephalopathy. It has been suggested that hyperammonaemia as well as systematic inflammation may lead to the activation of microglia. This activation induces to the local production of inflammatory mediators, that along with hyperammonaemia, negatively impact astrocyte function and contribute to the neurobehavioral deficits in hepatic encephalopathy. Adapted from Butterworth RF, Nat Rev Gastroenterol Hepatol 2013;10:522-528.

An association with sleep disorders has been reported in chronic hepatitis $B$, but evidence is weak [143].

Liver damage and impairment of detoxification processes are associated with increased concentrations of false neurotransmitters and toxins, which may influence sleeping patterns. Hyperammonemia leads to cerebral dysfunction, involving a spectrum of neuropsychiatric and neurological symptoms including an inversion of the sleep-wake rhythm [144].

Primary biliary cirrhosis and Wilson disease are also associated with sleep disturbances, which possibly represent a negative prognostic factor for these patients [145].

Non-alcoholic fatty liver disease (NAFLD) and non-alcoholic steatohepatitis (NASH) are associated with insulin resistance, glucose intolerance and the metabolic syndrome [146]. Sleep disorders in patients with steatohepatitis are likely related to impaired hepatocyte activity and impaired disposal of excess lipids. Alcohol has direct toxic effects on liver and CNS (Fig. 4). Several nuclear receptors expressed in the liver of patients with NAFLD and NASH influence the molecular clockwork throughout the day and may play a role in sleep disorders. [147] NASH and NAFLD are also related to OSA $[148,149]$. A recent meta-analysis of 9 studies (2272 participants) reported that OSA is significantly correlated with steatosis, lobular inflammation, ballooning degeneration and fibrosis [150].

Pruritus is common in patients with chronic liver disease, more so in those with cholestatic liver diseases such as primary biliary cholangitis. Impaired sleep and low QoL often ensue [151].

The prevalence of pruritus in liver diseases varies from $5 \%$ in chronic hepatitis $\mathrm{C}$ to $70 \%$ in primary biliary cirrhosis [152]. Increased concentrations of bile salts, histamine, serotonin, progesterone metabolites, and endogenous opioids are likely involved. However, a clear cause-effect link is lacking, as well as a correlation with the intensity of itching [153].

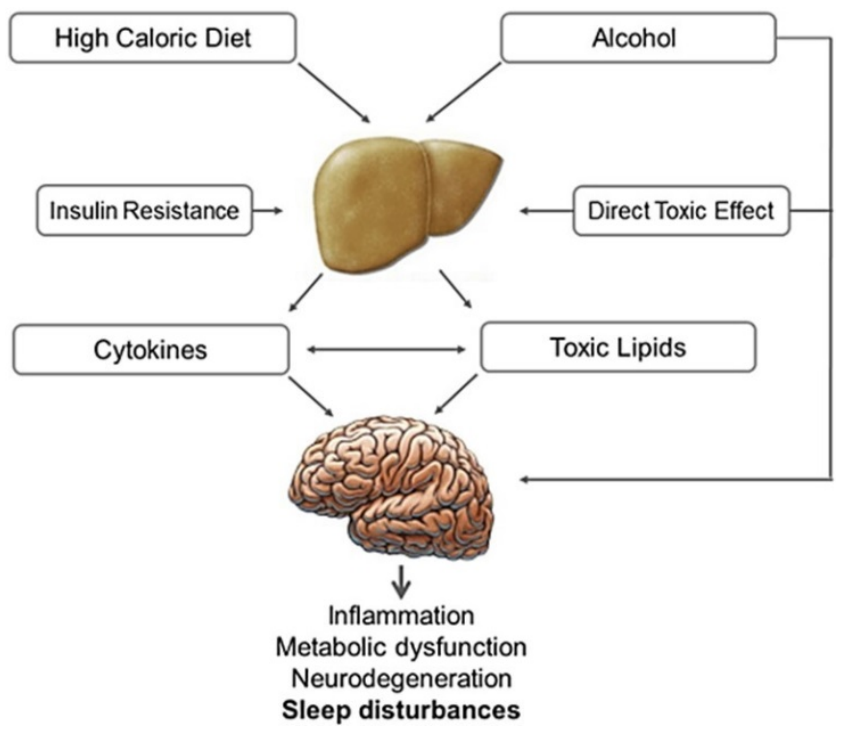

Figure 4. Effect of alcoholic and non-alcoholic steatohepatitis on brain function. High caloric and fat-rich diet and alcohol are the main causes of non-alcoholic and alcoholic steatohepatitis, which are proven to have a negative impact on brain function. Insulin plays an important role in both these conditions, compromising neural cell survival, metabolism and plasticity. In steatohepatitis the increased production of toxic lipids (e.g. ceramide), oxidative stress, as well as local cytokine production and activation, along with direct alcohol toxicity and depressant activity, may induce sleep disturbances, cognitive impairment and neurodegeneration.

\section{Pancreatic diseases}

Pain due to chronic pancreatitis is associated with impaired cognitive function, anxiety, depressive symptoms, and sleep disturbances [154].

Sleep quality is somewhat reduced in patients with severe pancreatic insufficiency undergoing home parenteral nutrition compared with aged-matched controls. Overall, sleep quality is not affected by home parenteral infusion [155]. OSA may be a risk factor for non-alcoholic fatty pancreatic disease, but the underlying mechanisms require clarification [156]. 


\section{Obesity}

Overweight and obesity favor sleep disorders through the increased prevalence of GERD and NAFLD, as well as OSA.

OSA is a common sleep disorder characterized by partial or complete upper airway occlusion during sleep, involving intermittent cessation (apnea) or reduction (hypopnea) of airflow and dips in arterial oxygen saturation during sleep [157].

Obesity and OSA have a reciprocal relationship. The sleep disruption of OSA promotes behavioral, metabolic, and/or hormonal changes, favoring weight gain and/or difficulty in losing it. OSA is associated with a hormonal profile characterized by high leptin and ghrelin levels, which in turn promote excess energy intake [158].

A $10 \%$ gain in body weight is associated with a $50 \%$ increase in the probability of developing OSA. Conversely, weight loss leads to less severe OSA, sleep improvement, and further weight loss. A relationship between OSA, short sleep duration and weight gain has thus been postulated $[39,159]$. Some evidence suggests that hypersomnolence is linked with obesity, also in the absence of sleep apnea [160].

\section{Medications}

Sleep is adversely affected by a variety of medications, hampering respiration, exacerbating or causing apnoea, inducing awakenings, and disrupting physiological sleep patterns. Muscle relaxants, by reducing muscle tone, can worsen OSA, a condition in which sedatives and hypnotics are contraindicated $[161,162]$. Alcohol and cigarette smoking (nicotinic acid) also display an unwanted myorelaxant effect [163]. Chronic opioid use is associated with disordered breathing during sleep and central sleep apnea [164].

Selective serotonin reuptake inhibitors are involved in sleep disorders [165], due to the central role of the serotoninergic system in the modulation of sleep, eating, emotional status and pain [166].

\section{Conclusions}

The link between diet, meal timing and sleep is reciprocal, as the circadian rhythm drives changes in the metabolic pattern, while modifications in the metabolic and nutritional status influence the circadian rhythm. Poor sleep is consistently related to changes in circulating melatonin, cortisol, ghrelin, and leptin, but the existence of additional mechanisms is likely.

Associations have also been found between short sleep duration, high total energy intake, and low-quality diet. Short sleepers often display irregular eating behaviors and take their main meal late in the day.

Sleep disturbances and sleep deprivation may either lead to, or worsen, visceral disorders but may in turn represent a symptom of disease. Chronic digestive diseases like GERD and peptic disease, functional and inflammatory GI disorders, liver diseases, often result in shorter, poor-quality sleep. Data, however, are mainly based on poor quality studies. Thus, adequately powered epidemiological studies and controlled trials focused on chronic short sleepers are needed to confirm causal relations. Sleep extension trials involving patients with GI disorders are needed as well to provide evidence on the relationship between GI disorders, diet and sleep duration and quality.

An integrated approach, involving sleepspecialists and gastroenterologists, using validated questionnaires and the ICSD-3 classification, is thus recommended to outline and categorize the specific sleep pattern impaired by, or involved in, GI disorders. A multi-specialist approach may indeed provide an insight on the complex bidirectional interaction between sleep disorders and GI tract diseases and, possibly, identify new therapeutic targets aimed at improving the quality of life of patients.

\section{Authors' Contributions}

F.V., M.D.R., A.C., and G.S. performed the literature review, wrote the manuscript, and prepared the Figures; A.V and G.F. reviewed the manuscript and provided critical comments; G.L. suggested the topic of the review and supervised, wrote, and critically reviewed the manuscript. All authors read and approved the final draft of the manuscript.

\section{Competing Interests}

The authors have declared that no competing interest exists.

\section{References}

1. Colten HR, Altevogt BM. Institute of medicine, committee on sleep medicine and research, board on health sciences policy. Sleep disorders and sleep deprivation: an unmet public health problem. Washington DC, USA: National Academies Press: 2006.

2. Olesen J, Gustavsson A, Svensson M, Wittchen HU, Jönsson B; CDBE 2010 Study Group. European brain council the economic cost of brain disorders in Europe. Eur J Neurol. 2012; 19: 155-162.

3. Cappuccio FP, D'Elia L, Strazzullo P, Miller MA. Sleep duration and all-cause mortality: a systematic review and meta-analysis of prospective studies. Sleep. 2010; 33: 585-592.

4. Ge L, Guyatt G, Tian J, Pan B, Chang $Y$, Chen $Y$, et al. Insomnia and risk of mortality from all-cause, cardiovascular disease, and cancer: Systematic review and meta-analysis of prospective cohort studies. Sleep Med Rev. 2019; 48:101215.

5. Schreier DR, Banks C, Mathis J. Driving simulators in the clinical assessment of fitness to drive in sleepy individuals: A systematic review. Sleep Med Rev. 2018; 38: 86-100.

6. Uehli K, Mehta AJ, Miedinger D, Hug K, Schindler C, Holsboer-Trachsler E, et al. Sleep problems and work injuries: a systematic review and meta-analysis. Sleep Med Rev. 2014; 18: 61-73. 
7. Hillman DR, Lack LC. Public health implications of sleep loss: the community burden. Med J Aust. 2013; 199(S): 7-10.

8. [Internet] Bellussi LM, De Benedetto M, Foresi A, Garbarino S, Insalaco G, Laurendi G, et al. La sindrome delle apnee ostruttive nel sonno (OSAS). 12 May 2016. www.apneedelsonno.it/doc/11_Osas_Finale_2016.pdf

9. Stranges S, Tigbe W, Gómez-Olivé FX, Thorogood M, Kandala NB. Sleep problems: an emerging global epidemic? Findings from the INDEPTH WHO-SAGE study among more than 40,000 older adults from 8 countries across Africa and Asia. Sleep. 2012; 35: 1173-1181.

10. American Academy of Sleep Medicine. International classification of sleep disorders, 3rd ed. Darien, USA: 2014

11. Sateia MJ. International classification of sleep disorders-third edition: highlights and modifications. Chest. 2014; 146: 1387-1394.

12. Candeias EM, Sebastião IC, Cardoso SM, Correia SC, Carvalho CI, Plácido AI, et al. Gut-brain connection: the neuroprotective effects of the anti-diabetic drug liraglutide. World J Diabetes. 2015; 6: 807-827.

13. Wang SZ, Yu YJ, Adeli K. Role of gut microbiota in neuroendocrine regulation of carbohydrate and lipid metabolism via the microbiota-gut-brain-liver axis. Microorganisms. 2020; 8: 527.

14. Sun LJ, Li JN, Nie YZ. Gut hormones in microbiota-gut-brain cross-talk. Chin Med J (Engl). 2020; 133: 826-833.

15. Smith RP, Easson C, Lyle SM, Kapoor R, Donnelly CP, Davidson EJ, Parikh E, et al. Gut microbiome diversity is associated with sleep physiology in humans. PLoS One. 2019; 14: e0222394.

16. Park H, Suh B. Association between sleep quality and physical activity according to gender and shift work. J Sleep Res. 2019: e12924.

17. Widome R, Lenk KM, Laska MN, Erickson DJ, Iber C, Kilian G, et al. Sleep duration and weight-related behaviors among adolescents. Child Obes. 2019; 15: 434-442.

18. Theorell-Haglöw J, Lemming EW, Michaëlsson K, Elmståhl S, Lind L, Lindberg E. Sleep duration is associated with healthy diet scores and meal patterns: results from the population-based EpiHealth study. Clin Sleep Med. 2020; 16: 9-18.

19. Dashti HS, Scheer FA, Jacques PF, Lamon-Fava S, Ordovás JM. Short sleep duration and dietary intake: epidemiologic evidence, mechanisms, and health implications. Adv Nutr. 2015; 6: 648-659.

20. Chaput JP. Sleep patterns, diet quality and energy balance. Physiol Behav. 2014; 134: 86-91.

21. Ongan D, Yuksel A. What to eat for a better sleep in haemodialysis patients: potential role of B vitamins intake and appetite. Pak J Med Sci. 2017; 33: $417-424$

22. Aspy DJ, Madden NA, Delfabbro P. Effects of vitamin B6 (pyridoxine) and a B complex preparation on dreaming and sleep. Percept Mot Ski. 2018; 125: 451462.

23. Young DR, Sidell MA, Grandner MA, Koebnick C, Troxel W. Dietary behaviors and poor sleep quality among young adult women: watch that sugary caffeine! Sleep Health. 2020; 6: 214-219.

24. Gross G, Maruani J, Vorspan F, Benard V, Benizri C, Brochard H, et al. Association between coffee, tobacco, and alcohol daily consumption and sleep/wake cycle: an actigraphy study in euthymic patients with bipolar disorders. Chronobiol Int. 2020; 37: 712-722.

25. Edwards SJ, Montgomery IM, Colquhoun EQ, Jordan JE, Clark MG. Spicy meal disturbs sleep: an effect of thermoregulation? Int J Psychophysiol. 1992; 13: $97-100$.

26. Ekmekcioglu C, Touitou Y. Chronobiological aspects of food intake and metabolism and their relevance on energy balance and weight regulation. Obes Rev. 2011; 12: 14-25.

27. St-Onge MP, Ard J, Baskin ML, Chiuve SE, Johnson HM, KrisEtherton P, et al. Meal timing and frequency: implications for cardiovascular disease prevention: a scientific statement from the American Heart Association. Circulation 2017;135: e96-121.

28. St-Onge MP, Roberts A, Shechter A, Choudhury AR. Fiber and saturated fat are associated with sleep arousals and slow wave sleep. J Clin Sleep Med. 2016; 12: 19-24.

29. Lindseth G, Murray A. Dietary macronutrients and sleep. West J Nurs Res. 2016; 38: 938-958.

30. Daneshzad E, Keshavarz SA, Qorbani M, Larijani B, Azadbakht L. The association between Low Carbohydrate diet, sleep status, depression, anxiety and stress score. J Sci Food Agric. 2020; 100: 2946-2952.

31. Nowak J, Dimitrov A, Oei NYL, Walter H, Adli M, Veer IM. Association of naturally occurring sleep loss with reduced amygdala resting-state functional connectivity following psychosocial stress. Psychoneuroendocrinology. 2020; 114: 104585

32. Thivel D, Chaput JP. Food consumption in children and youth: effect of sedentary activities. Rev Epidemiol Sante Publique. 2013; 61: 399-405.

33. Yang $Y$, Miao Q, Zhu X, Qin L, Gong W, Zhang S, et al. Sleeping time, BMI, and body fat in Chinese freshmen and their interrelation. Obes Facts. 2020; 13: $179-190$

34. Felso R, Lohner S, Hollody K, Erhardt E, Molnár D. Relationship between sleep duration and childhood obesity: Systematic review including the potential underlying mechanisms. Nutrition, metabolism, and cardiovascular diseases: NMCD 2017; 27: 751-761.

35. Saderi N, Escobar C, Salgado-Delgado R. Alteration of biological rhythms causes metabolic diseases and obesity. Rev Neurol. 2013; 57: 71-78.
36. Domínguez-Ortega G, Borrelli O, Meyer R, Dziubak R, De Koker C, Godwin $\mathrm{H}$, et al. Extraintestinal manifestations in children with gastrointestinal food allergy. J Pediatr Gastroenterol Nutr. 2014; 59: 210-214.

37. Johnston JD. Physiological responses to food intake throughout the day. Nutr Res Rev 2014; 27: 107-118

38. Fonken LK, Nelson RJ. The effects of light at night on circadian clocks and metabolism. Endocr Rev. 2014; 35: 648-670.

39. St-Onge MP, Shechter A. Sleep disturbances, body fat distribution, food intake and/or energy expenditure: pathophysiological aspects. Horm Mol Biol Clin Investig. 2014; 17: 29-37.

40. Depner CM, Stothard ER, Wright KP. Metabolic consequences of sleep and circadian disorders. Curr Diab Rep. 2014; 14: 507.

41. Deng HB, Tam T, Zee BC, Chung RY, Su X, Jin L, et al. Short sleep duration increases metabolic impact in healthy adults: a population-based cohort study. Sleep 2017; 40. doi: 10.1093/sleep/zsx130.

42. Miller AL, Lumeng JC, LeBourgeois MK. Sleep patterns and obesity in childhood. Curr Opin Endocrinol Diabetes Obes. 2015; 22: 41-47.

43. Tahara Y, Shibata S. Chrono-biology, chrono-pharmacology, and chrononutrition. J Pharmacol Sci. 2014; 124: 320-335.

44. Poggiogalle E, Jamshed H, Peterson CM. Circadian regulation of glucose, lipid, and energy metabolism in humans. Metabolism. 2018; 84: 11-27.

45. Schmid SM, Hallschmid M, Schultes B. The metabolic burden of sleep loss. Lancet Diabetes Endocrinol. 2015; 3: 52-62.

46. Ulhôa MA, Marqueze EC, Burgos LG, Moreno CR. Shift work and endocrine disorders. Int J Endocrinol. 2015; 2015: 826249.

47. Copinschi G, Leproult R, Spiegel K. The important role of sleep in metabolism. Front Horm Res. 2014; 42: 59-72.

48. Knutson KL, Van Cauter E. Associations between sleep loss and increased risk of obesity and diabetes. Ann N Y Acad Sci. 2008; 1129: 287-304

49. Lin J, Jiang $\mathrm{Y}$, Wang G, Meng M, Zhu Q, Mei H, et al. Associations of short sleep duration with appetite-regulating hormones and adipokines: A systematic review and meta-analysis. Obes Rev. 2020; 21: e13051.

50. Toyoura M, Miike T, Tajima S, Matsuzawa S, Konishi Y. Inadequate sleep as a contributor to impaired glucose tolerance: A cross-sectional study in children, adolescents, and young adults with circadian rhythm sleep-wake disorder. Pediatr Diabetes. 2020; 21: 557-564.

51. Zimmet P, Alberti KGMM, Stern N, Bilu C, El-Osta A, Einat $\mathrm{H}$, et al. The Circadian Syndrome: is the Metabolic Syndrome and much more! J Intern Med. 2019; 286: 181-191.

52. Steiger A, Dresler M, Schüssler P, Kluge M. Ghrelin in mental health, sleep, memory. Mol Cell Endocrinol. 2011; 340: 88-96.

53. Passani MB, Blandina P. Histamine receptors in the CNS as targets for therapeutic intervention. Trends Pharmacol Sci. 2011; 32: 242-249.

54. Schlicker E, Kathmann M. Role of the histamine H(3) receptor in the central nervous system. Handb Exp Pharmacol. 2017; 241: 277-299.

55. Kanaly T, Shaheen NJ, Vaughn BV. Gastrointestinal physiology and digestive disorders in sleep. Curr Opin Pulm Med. 2009; 15: 571-577.

56. Brown JA, Woodworth HL, Leinninger GM. To ingest or rest? Specialized roles of lateral hypothalamic area neurons in coordinating energy balance. Front Syst Neurosci. 2015; 9: 9.

57. Tsujino N, Sakurai T. Orexin/hypocretin: a neuropeptide at the interface of sleep, energy homeostasis, and reward system. Pharmacol Rev. 2009; 61: $162-176$

58. Chieffi S, Carotenuto M, Monda V, Valenzano A, Villano I, Precenzano F, et al. Orexin system: the key for a healthy life. Front Physiol. 2017; 8: 357.

59. Hoyer D, Jacobson LH. Orexin in sleep, addiction and more: is the perfect insomnia drug at hand? Neuropeptides. 2013; 47: 477-488.

60. Peuhkuri K, Sihvola N, Korpela R. Diet promotes sleep duration and quality. Nutr Res. 2012: 32: 309-319.

61. Beebe DW, Simon S, Summer S, Hemmer S, Strotman D, Dolan LM. Dietary intake following experimentally restricted sleep in adolescents. Sleep. 2013; 36: 827-834.

62. Kjeldsen JS, Hjorth MF, Andersen R, Michaelsen KF, Tetens I, Astrup A, et al. Short sleep duration and large variability in sleep duration are independently associated with dietary risk factors for obesity in Danish school children. Int J Obes (Lond). 2014; 38: 32- 39.

63. Smith SL, Ludy MJ, Tucker RM. Changes in taste preference and steps taken after sleep curtailment. Physiol Behav. 2016; 163: 228-233.

64. Pigarev IN, Pigareva ML. The sleep and the visceral function control. Ross Fiziol Zh Im I M Sechenova. 2011; 97: 374-387.

65. Dai H, Mei Z, An A, Wu J. Association between sleep problems and healthrelated quality of life in Canadian adults with chronic diseases. Sleep Med. 2019; 61: 26-30

66. Parish JM. Sleep-related problems in common medical conditions. Chest. 2009; 135: 563-572.

67. Gerson LB, Fass R. A systematic review of the definitions, prevalence, and response to treatment of nocturnal gastroesophageal reflux disease. Clin Gastroenterol Hepatol. 2009; 7: 372-378.

68. Yamasaki T, Quan SF, Fass R. The effect of sleep deficiency on esophageal acid exposure of healthy controls and patients with gastroesophageal reflux disease. Neurogastroenterol Motil. 2019; 31: e13705.

69. Fujiwara Y, Arakawa T, Fass R. Gastroesophageal reflux disease and sleep disturbances. J Gastroenterol. 2012; 47: 760-769.

70. On ZX, Grant J, Shi Z, Taylor AW, Wittert GA, Tully PJ, et al. The association between gastroesophageal reflux disease with sleep quality, depression, and 
anxiety in a cohort study of Australian men. J Gastroenterol Hepatol. 2017; 32: 1170-1177.

71. Okuyama M, Takaishi O, Nakahara K, Iwakura N, Hasegawa T, Oyama M, et al. Associations among gastroesophageal reflux disease, psychological stress, and sleep disturbances in Japanese adults. Scand J Gastroenterol. 2017; 52: 44-49.

72. Hoshino M, Omura N, Yano F, Tsuboi K, Yamamoto SR, Akimoto S, et al. The evaluation of recumbent reflux by multichannel intraluminal impedance $\mathrm{pH}$ testing for patients with gastroesophageal reflux disease and sleep disturbance. Esophagus. 2020; 17: 348-354

73. Romdhane $\mathrm{H}$, Ben Abdallah $\mathrm{H}$, Abdelli MN. Nocturnal gastroesophageal reflux and sleep apnea: what relationship? Tunis Med. 2012; 90: 598-601.

74. Regenbogen E, Helkin A, Georgopoulos R, Vasu T, Shroyer AL. Esophageal reflux disease proton pump inhibitor therapy impact on sleep disturbance: a systematic review. Otolaryngol Head Neck Surg. 2012; 146: 524-532.

75. Najm WI. Peptic ulcer disease. Prim Care. 2011; 38: 383-394.

76. Zolotarev VA. Dietary free amino acids and the gastric phase of digestion. Curr Pharm Des. 2014; 20: 2731-2737.

77. Feinle-Bisset C. Upper gastrointestinal sensitivity to meal-related signals in adult humans - relevance to appetite regulation and gut symptoms in health, obesity and functional dyspepsia. Physiol Behav. 2016; 162: 69-82.

78. Ko SH, Baeg MK, Ko SY, Han KD. Women who sleep more have reduced risk of peptic ulcer disease; korean national health and nutrition examination survey (2008-2009). Sci Rep. 2016; 6: 36925.

79. Konturek PC, Brzozowski T, Konturek SJ. Gut clock: implication of circadian rhythms in the gastrointestinal tract. J Physiol Pharmacol. 2011; 62: 139-150.

80. Wu S, Chen S, Zhao Y, Ma X, Wang R, He J. Association between excessive daytime sleepiness and functional gastrointestinal disorders: a populationbased study in China. J Neurogastroenterol Motil. 2017; 23: 298-305.

81. Futagami S, Shimpuku M, Yamawaki H, Izumi N, Kodaka Y, Nagoya H, et al. Sleep disorders in functional dyspepsia and future therapy. J Nippon Med Sch. 2013; 80: 104-109.

82. Lacy BE, Everhart K, Crowell MD. Functional dyspepsia is associated with sleep disorders. Clin Gastroenterol Hepatol 2011; 9: 410-414

83. Madsen JL, Damgaard M, Fuglsang S, Dirksen C, Holst JJ, Graff J. Gastrointestinal motility, gut hormone secretion, and energy intake after oral loads of free fatty acid or triglyceride in older and middle-aged men. Appetite. 2019; 132: 18-24.

84. Tu Q, Heitkemper MM, Jarrett ME, Buchanan DT. Sleep disturbances in irritable bowel syndrome: a systematic review. Neurogastroenterol Motil. 2017;29. doi: 10.1111/nmo.

85. Balikji S, Mackus M, Brookhuis KA, Garssen J, Kraneveld AD, Roth T, et al. The association of insomnia perceived immune functioning, and Irritable Bowel Syndrome complaints. J Clin Med. 2018; 7: 238

86. Bouchoucha M, Mary F, Bon C, Bejou B, Airinei G, Benamouzig R. Sleep quality and functional gastrointestinal disorders. a psychological issue. J Dig Dis. 2018; 19: 84-92.

87. Zhou HQ, Yao M, Chen YW, Huang JY, Chen GY. Functional gastrointestinal disorders common among nurses with poor sleep quality in Shanghai, China: a pilot study. Gastroenterol Nurs. 2017; 40: 312-319.

88. Wang B, Duan R, Duan L. Prevalence of sleep disorder in irritable bowel syndrome: A systematic review with meta-analysis. Saudi J Gastroenterol. 2018; 24 : 141-150.

89. Okumura T, Nozu T. Role of brain orexin in the pathophysiology of functional gastrointestinal disorders. J Gastroenterol Hepatol. 2011; 26: 61-66.

90. Siah KT, Wong RK, Ho KY. Melatonin for the treatment of irritable bowel syndrome. World J Gastroenterol. 2014; 20: 2492-2498.

91. Wilhelmsen M, Amirian I, Reiter RJ, Rosenberg J, Gögenur I. Analgesic effects of melatonin: a review of current evidence from experimental and clinical studies. J Pineal Res. 2011; 51: 270-277.

92. Eswaran S, Chey WD, Jackson K, Pillai S, Chey SW, Han-Markey T. A diet low in fermentable oligo-, di-, and monosaccharides and polyols improves quality of life and reduces activity impairment in patients with irritable bowel syndrome and diarrhea. Clin Gastroenterol Hepatol. 2017; 15: 1890-1899.e3.

93. Vernia P, Di Camillo M, Foglietta T, Avallone VE, De Carolis A. Diagnosis of lactose intolerance and the "nocebo" effect: the role of negative expectations. Dig Liver Dis. 2010; 42: 616-619.

94. Roizenblatt M, Rosa Neto NS, Tufik S, Roizenblatt S. Pain-related diseases and sleep disorders. Braz J Med Biol Res. 2012; 45: 792-798.

95. Galland L. The gut microbiome and the brain. J Med Food. 2014; 17: 1261-1272.

96. Ghoshal UC, Ghoshal U. Small intestinal bacterial overgrowth and other intestinal disorders. Gastroenterol Clin North Am. 2017; 46: 103-120.

97. Ali T, Choe J, Awab A, Wagener TL, Orr WC. Sleep, immunity and inflammation in gastrointestinal disorders. World J Gastroenterol. 2013; 19: 9231-9239.

98. Ali T, Orr WC. Sleep disturbances and inflammatory bowel disease. Inflamm Bowel Dis. 2014; 20: 1986-1995.

99. Swanson GR, Burgess HJ, Keshavarzian A. Sleep disturbances and inflammatory bowel disease: a potential trigger for disease flare? Expert Rev Clin Immunol. 2011; 7: 29-36.

100. Sofia MA, Lipowska AM, Zmeter N, Perez E, Kavitt R, Rubinet DT. Poor sleep quality in Crohn's disease is associated with disease activity and risk for hospitalization or surgery. Inflamm Bowel Dis. 2020; 26: 1251-1259.
101. Michalopoulos G, Vrakas S, Makris K, Tzathas C. Association of sleep quality and mucosal healing in patients with inflammatory bowel disease in clinical remission. Ann Gastroenterol. 2018; 31: 211-216.

102. Stevens BW, Borren NZ, Velonias G, Conway G, Cleland T, Andrews E, et al. Vedolizumab therapy is associated with an improvement in sleep quality and mood in inflammatory bowel diseases. Dig Dis Sci. 2017; 62: 197-206.

103. Iskandar HN, Linan EE, Patel A, Moore R, Lasanajak Y, Gyawali CP, Sayuk GS, Ciorba MA. Self-reported sleep disturbance in Crohn's disease is not confirmed by objective sleep measures. Sci Rep. 2020; 10: 1980.

104. Zargar A, Gooraji SA, Keshavarzi B, Haji Aghamohammadi AA. Effect of irritable bowel syndrome on sleep quality and quality of life of Inflammatory Bowel Disease in clinical remission. Int J Prev Med. 2019; 10:10.

105. Parisi P, Pietropaoli N, Ferretti A, Nenna R, Mastrogiorgio G, Del Pozzo M, et al. Role of the gluten-free diet on neurological-EEG findings and sleep disordered breathing in children with celiac disease. Seizure. 2015; 25: 181-183.

106. Mårild K, Morgenthaler TI, Somers VK, Kotagal S, Murray JA, Ludvigsson JF. Increased use of hypnotics in individuals with celiac disease: a nationwide case-control study. BMC Gastroenterol. 2015; 15: 10.

107. Zingone F, Siniscalchi M, Capone P, Tortora R, Andreozzi P, Capone E, et al. The quality of sleep in patients with coeliac disease. Aliment Pharmacol Ther. 2010; 32: 1031-1036.

108. Zylberberg HM, Demmer RT, Murray JA, Green PHR, Lebwohl B. Depression and insomnia among individuals with celiac disease or on a gluten-free diet in the USA: results from a national survey. Eur J Gastroenterol Hepatol. 2017; 29: 1091-1096.

109. Yerushalmy-Feler A, Tauman R, Derowe A, Averbuch E, Ben-Tov A, Weintraub Y, Weiner D, Amir A, Moran-Lev H, Cohen S. Gluten-free diet may improve obstructive sleep apnea-related symptoms in children with celiac disease. BMC Pediatr. 2018; 18: 35.

110. Strandwitz, P. Neurotransmitter modulation by the gut microbiota. Brain Res. 2018; 1693: 128-133.

111. van de Wouw M, Boehme M, Lyte JM, Wiley N, Strain C, O'Sullivan O, et al. Short-chain fatty acids: microbial metabolites that alleviate stress-induced brain-gut axis alterations. J Physiol. 2018; 596: 4923-4944.

112. Telle-Hansen VH, Holven KB, Ulven SM. Impact of a healthy dietary pattern on gut microbiota and systemic inflammation in humans. Nutrients. 2018; 10: 1783.

113. Bowers SJ, Vargas F, González A, He S, Jiang P, Dorrestein PC, et al. Repeated sleep disruption in mice leads to persistent shifts in the fecal microbiome and metabolome. PLoS One. 2020; 15: e0229001.

114. Mayer EA, Tillisch K, Gupta A. Gut/brain axis and the microbiota. J Clin Invest. $2015 ; 125$ : 926-938.

115. Fetissov SO, Déchelotte P. The new link between gut-brain axis and neuropsychiatric disorders. Curr Opin Clin Nutr Metab Care. 2011; 14: 477-482.

116. Chen X, D'Souza R, Hong ST. The role of gut microbiota in the gut-brain axis: current challenges and perspectives. Protein Cell. 2013; 4: 403-414.

117. Ouabbou $\mathrm{S}, \mathrm{He} \mathrm{Y}$, Butler $\mathrm{K}$, Tsuang $\mathrm{M}$. Inflammation in mental disorders: is the microbiota the missing link? Neurosci Bull. 2020; 36: 1071-1084.

118. Simpson CA, Schwartz OS, Simmons JG. The human gut microbiota and depression: widely reviewed, yet poorly understood. J Affect Disord. 2020; 274: 73-75.

119. Wallace CJK, Milev R. The effects of probiotics on depressive symptoms in humans: a systematic review. Ann Gen Psychiatry. 2017; 16: 14.

120. Liu Z, Wei ZY, Chen J, Chen K, Mao X, Liu Q, et al. Acute sleep-wake cycle shift results in community alteration of human gut microbiome. mSphere. 2020; 5: e00914-19.

121. Reynolds AC, Paterson JL, Ferguson SA, Stanley D, Wright KP Jr, Dawson D. The shift work and health research agenda: considering changes in gut microbiota as a pathway linking shift work, sleep loss and circadian misalignment, and metabolic disease. Sleep Med Rev. 2016; 34: 3-9.

122. Hurtado-Alvarado G, Domínguez-Salazar E, Pavon L, Velázquez-Moctezuma J, Gómez-González B. Blood-brain barrier disruption induced by chronic sleep loss: low-grade inflammation may be the link. J Immunol Res. 2016; 2016: 4576012.

123. Durgan DJ. Obstructive sleep apnea-induced hypertension: role of the gut microbiota. Curr Hypertens Rep. 2017; 19: 35.

124. Reutrakul S, So-Ngern A, Chirakalwasan N, Saetung S, Chanprasertyothin S, Thakkinstian A, et al. No changes in gut microbiota after two-week sleep extension in chronically sleep-deprived individuals. Sleep Med. 2019; 68: 27-30.

125. Xiao G, Ye Q, Han T, Yan J, Sun L, Wang F. Study of the sleep quality and psychological state of patients with hepatitis B liver cirrhosis. Hepatol Res. 2018; 48: E275-E282.

126. Saleh K, Javaheri S. Sleep in ambulatory patients with stable cirrhosis of the liver. Sleep Med. 2018; 41: 15-19.

127. Vilstrup H, Amodio P, Bajaj J, Cordoba J, Ferenci P, Mullen KD, et al. Hepatic encephalopathy in chronic liver disease: 2014 practice guideline by the American association for the study of liver diseases and the European association for the study of the liver. Hepatology. 2014; 60: 715-735.

128. Waghray A, Waghray N, Mullen K. Management of covert hepatic encephalopathy. J Clin Exp Hepatol 2015; 5: S75-81.

129. Stewart CA, Malinchoc M, Kim WR, Kamath PS. Hepatic encephalopathy as a predictor of survival in patients with end-stage liver disease. Liver Transplantation. 2007; 13: 1366-1371. 
130. Labenz C, Baron JS, Toenges G, Schattenberg JM, Nagel M, Sprinzl MF, et al. Prospective evaluation of the impact of covert hepatic encephalopathy on quality of life and sleep in cirrhotic patients. Aliment Pharmacol Ther. 2018; 48: 313-321.

131. Montagnese S, De Pittà C, De Rui M, Corrias M, Turco M, Merkel C, et al. Sleep-wake abnormalities in patients with cirrhosis. Hepatology. 2014; 59: 705-712.

132. Montagnese S, Middleton B, Mani AR, Skene DJ, Morgan MY. On the origin and the consequences of circadian abnormalities in patients with cirrhosis. Am J Gastroenterol. 2010; 105: 1773-1781.

133. Rai R, Saraswat VA, Dhiman RK. Gut microbiota: its role in hepatic encephalopathy. J Clin Exp Hepatol. 2015; 5: S29-36.

134. Singh J, Sharma BC, Puri V, Sachdeva S, Srivastava S. Sleep disturbances in patients of liver cirrhosis with minimal hepatic encephalopathy before and after lactulose therapy. Metab Brain Dis. 2017; 32: 595-605.

135. Bruyneel M, Sersté T, Libert W, van den Broecke S, Ameye L, Dachy B, et al. Improvement of sleep architecture parameters in cirrhotic patients with recurrent hepatic encephalopathy with the use of rifaximin. Eur J Gastroenterol Hepatol. 2017; 29: 302-308.

136. Ichikawa T, Naota T, Miyaaki H, Miuma S, Isomoto H, Takeshima F, et al. Effect of an oral branched chain amino acid-enriched snack in cirrhotic patients with sleep disturbance. Hepatol Res. 2010; 40: 971-978.

137. Dalal R, McGee RG, Riordan SM, Webster AC. Probiotics for people with hepatic encephalopathy. Cochrane Database Syst Rev. 2017; 2: CD008716.

138. Sockalingam S, Abbey SE, Alosaimi F, Novak M. A review of sleep disturbance in hepatitis C. J Clin Gastroenterol. 2010; 44: 38-45.

139. Costa M, Rojas TR, Lacoste D, Villes V, Aumaitre H, Protopopescu C, et al. Sleep disturbances in HIV-HCV coinfected patients: indications for clinical management in the HCV cure era (ANRS CO13 HEPAVIH cohort). Eur J Gastroenterol Hepatol. 2019; 31: 1508-1517.

140. Yoh $\mathrm{K}$, Nishikawa $\mathrm{H}$, Enomoto $\mathrm{H}$, et al. Comparison of sleep disorders in chronic hepatitis $C$ patients treated with interferonbased therapy and direct acting antivirals using actigraphy. Hepatol Res. 2016; 46: 1358-1366.

141. D'Mello C, Swain MG. Liver-brain interactions in inflammatory liver diseases: implications for fatigue and mood disorders. Brain Behav Immun. 2014; 35: 9-20.

142. Butterworth RF. The liver-brain axis in liver failure: neuroinflammation and encephalopathy. Nat Rev Gastroenterol Hepatol. 2013; 10: 522-528.

143. Huang X, Zhang H, Qu C, Liu Y, Bian C, Xu Y. Depression and insomnia are closely associated with thyroid hormone levels in chronic hepatitis B. Med Sci Monit. 2019; 25: 2672-2678.

144. Bosoi CR, Rose CF. Identifying the direct effects of ammonia on the brain. Metab Brain Dis. 2009; 24: 95-102.

145. De Cruz S, Espiritu JR, Zeidler M, Wang TS. Sleep disorders in chronic liver disease. Semin Respir Crit Care Med. 2012; 33: 26-35.

146. Wong VW, Chitturi S, Wong GL, Wang TS. Pathogenesis and novel treatment options for non-alcoholic steatohepatitis. Lancet Gastroenterol Hepatol. 2016; 1: 56-67.

147. Mazzoccoli G, Vinciguerra M, Oben J, Tarquini R, De Cosmo S. Non-alcoholic fatty liver disease: the role of nuclear receptors and circadian rhythmicity. Liver Int. 2014; 34: 1133-1152.

148. Wei YT, Lee PY, Lin CY, Chen HJ, Lin CC, Wu JS, et al. Non-alcoholic fatty liver disease among patients with sleep disorders: a nationwide study of Taiwan. BMC Gastroenterol. 2020;20: 32

149. Zhang L, Zhang X, Meng H, Li Y, Han T, Wang C. Obstructive sleep apnea and liver injury in severely obese patients with nonalcoholic fatty liver disease. Sleep Breath. 2020; [Epub ahead of print].

150. Jin S, Jiang S, Hu A. Association between obstructive sleep apnea and nonalcoholic fatty liver disease: a systematic review and meta-analysis. Sleep Breath. 2018. 22: 841-851.

151. Tajiri K, Shimizu Y. Recent advances in the management of pruritus in chronic liver diseases. World J Gastroenterol. 2017; 23: 3418-3426.

152. Trivedi HD, Lizaola B, Tapper EB, Bonder A. Management of pruritus in primary biliary cholangitis: a narrative review. Am J Med. 2017; 130: 744.e1-744.e7.

153. Kremer AE, Namer B, Bolier R, Fischer MJ, Oude Elferink RP, Beuers U. Pathogenesis and Management of Pruritus in PBC and PSC. Dig Dis. 2015; 33: 164-175.

154. Jongsma ML, Postma SA, Souren P, Arns M, Gordon E, Vissers K, et al. Neurodegenerative properties of chronic pain: cognitive decline in patients with chronic pancreatitis. PLoS One. 2011; 6: e23363.

155. Scolapio JS, Savoy AD, Kaplan J, Burger CD, Lin SC. Sleep patterns of cyclic parenteral nutrition, a pilot study: are there sleepless nights? J Parenter Enteral Nutr. 2002; 26: 214-217.

156. Mirrakhimov AE. Nonalcoholic fatty pancreatic disease and cardio-metabolic risk: is there is a place for obstructive sleep apnea? Cardiovasc Diabetol. 2014; 13: 29.

157. Mason M, Cates CJ, Smith I. Effects of opioid, hypnotic and sedating medications on sleep-disordered breathing in adults with obstructive sleep apnoea. Cochrane Database Syst Rev. 2015; 7: CD011090.

158. Shechter A. Obstructive sleep apnea and energy balance regulation: a systematic review. Sleep Med Rev. 2017; 34: 59-69.

159. Pugliese G, Barrea L, Laudisio D, Salzano C, Aprano S, Colao A, et al. Sleep apnea, obesity, and disturbed glucose homeostasis: epidemiologic evidence, biologic insights, and therapeutic strategies. Curr Obes Rep. 2020; 9: 30-38.
160. Panossian LA, Veasey SC. Daytime sleepiness in obesity: mechanisms beyond obstructive sleep apnea - a review. Sleep. 2012; 35: 605-615.

161. Weatherspoon D, Sullivan D, Weatherspoon CA. Obstructive sleep apnea and modifications in sedation: an update. Crit Care Nurs Clin North Am. 2016; 28: 217-226.

162. McEntire DM, Kirkpatrick DR, Kerfeld MJ, Hambsch ZJ, Reisbig MD, Agrawal DK, et al. Effect of sedative-hypnotics, anesthetics and analgesics on sleep architecture in obstructive sleep apnea. Expert Rev Clin Pharmacol. 2014; 7: 787-806.

163. Deleanu OC, Pocora D, Mihălcută S, Ulmeanu R, Zaharie AM, Mihălțan FD. Influence of smoking on sleep and obstructive sleep apnea syndrome. Pneumologia. 2016; 65: 28-35.

164. Correa D, Farney RJ, Chung F, Prasad A, Lam D, Wong J. Chronic opioid use and central sleep apnea: a review of the prevalence, mechanisms, and perioperative considerations. Anesth Analg. 2015; 120: 1273-1285.

165. Serretti A, Artioli P, De Ronchi D. The 5-HT2C receptor as a target for mood disorders. Expert Opin Ther Targets. 2004; 8: 15-23.

166. Cifariello A, Pompili A, Gasbarri A. 5-HT(7) receptors in the modulation of cognitive processes. Behav Brain Res. 2008; 195: 171-179. 